An important question in familial translocations is the mode of segregation and its implications for genetic counselling. The relative frequency of unbalanced gametes depends both on the type of the multivalent formed and its orientation on the metaphase plate, but the more important factor for predicting the prospective risk for carriers of a reciprocal translocation is the degree of possible resulting chromosomal imbalance. In reciprocal translocations causing trisomy for distal $12 q$, the centric segments are larger than the translocated ones and all the probands result from adjacent 1 segregation, which, in such a situation, would cause the least imbalanced karyotypes at birth. Another factor to be considered is the sex of the carrier parent. In seven of the 10 affected families trisomy for the distal region of $12 q$ was the consequence of a maternal translocation. This preponderance of maternal origin has also been noted for other trisomies due to malsegregation of the $3: 1$ type, but is not common among translocations of the $2: 2$ type. ${ }^{3}$ As mean maternal age is not increased and there is no obvious bias of ascertainment, the more probable determining factor is the difference between male and female meiosis which results in decreased fertility or even sterility among men carrying these rearrangements. This was noted in the family history of some probands. ${ }^{710}$

The authors wish to thank Dr James Robert Coleman for improving the English and the Conselho Nacional de Desenvolvimento Científico e Tecnológico ( $\mathrm{CNPq}$ ) for financial support.

\author{
References \\ 1 Hirschhorn K, Lucas M, Wallace I. Precise identification of \\ various chromosomal abnormalities. Ann Hum Genet \\ 1973;36:375-9. \\ 2 Hobolth N, Jacobsen P, Mikkelsen M. Partial trisomy 12 in a
}

mentally retarded boy and translocation $(12 ; 21)$ in his mother. $J$ Med Genet 1974;11:299-303.

${ }^{3}$ Aurias A, Prieur M, Dutrillaux B, Lejeune J. Systematic analysis of 95 reciprocal translocations of autosomes. Hum Genet 1978;45:259-82.

${ }^{4}$ Hemming L, Brown R. Partial trisomy $12 \mathrm{q}$ associated with a familial translocation. Clin Genet 1979;16:25-8.

${ }^{5}$ Harrod MJE, Byrne JB, Dev VG, Francke V. Duplication 12q mosaicism in two unrelated patients with a similar syndrome. Am J Med Genet 1980;7:123-9.

${ }^{6}$ de Muelenaere A, Fryns JP, Van den Berghe H. Partial distal 12q trisomy. Ann Genet (Paris) 1980;23:251-3.

${ }^{7}$ Melnyck AR, Weiss L, Van Dyke DL, Jarvi P. Malformation syndrome of duplication 12q24.1 $\rightarrow$ qter. Am J Med Gene 1981;10:357-65.

${ }^{8}$ Roberts SH, Mattina T, Laurence KM, Sorge G, Pavone L. Partial trisomy 12q: report of a case and review. J Med Gener 1981;18:470-3.

${ }^{9}$ Zabel B, Baumann W. Partial trisomy 12q. J Med Genet 1981;18:144-57.

10 Pratt NR, Bulugahapitiya DTD. Partial trisomy 12q: a clinically recognisable syndrome. Genetic risks associated with translocations of chromosome 12q. J Med Genet 1983;20:86-9.

1 ISCN (1981). An International System for Human Cytogenetic Nomenclature: high resolution banding. Cytogenet Cell Genet 1981;31:1-23.

12 Taillemite JL, Tufferaud G, Hazael-Massieux P, BaheuxMorlier G, Roux C. Délétion partielle du bras court du chromosome 4. A propos de trois observations. Ann Genet (Paris) 1977;20:93-100.

13 Stoll C. Nonrandom distribution of exchange points in patients with reciprocal translocations. Hum Genet 1980;56:89-93.

${ }^{14}$ Ford JH, Rofe RH, Pavi RP. Translocations involving chromosome 12. I. A report of a 12;21 translocation in a woman with recurrent abortions and a study of the breakpoints and modes of ascertainment of translocations involving chromosome 12. Hum Genet 1981;58:144-8.

15 Biederman B, Bowen P. Balanced translocations involving chromosome 12: report of a case and possible evidence for position effect. Ann Genet (Paris) 1976;19:257-60.

${ }^{16}$ Ford J. Translocations of chromosome 12. II. A comparison of the distribution of sites of spontaneous and induced breakages. Hum Genet 1981;58:279-81.

Correspondence and requests for reprints to $\operatorname{Dr} M$ Varella-Garcia, Departamento de Biologia, Instituto de Biociências, Letras e Ciências Exatas (UNESP), 15.100 São José do Rio Preto, São Paulo, Brazil.

\title{
Fraser syndrome presenting as monozygotic twins with bilateral renal agenesis
}

\section{G MORTIMER*, H P McEWAN†, AND J R W YATES}

Departments of Pathology* and Obstetricst, Royal Maternity Hospital, Glasgow G4 ONA; and $\ddagger D u n c a n$ Guthrie Institute of Medical Genetics, Yorkhill, Glasgow G3 8SJ.

SUMMARY Fraser syndrome without cryptophthalmos is described in monozygotic twins concordant for bilateral renal agenesis.

Received for publication 30 May 1984.

Accepted for publication 28 June 1984.
The cryptophthalmos syndrome is an autosomal recessive condition, ${ }^{1}$ the main features of which are cryptophthalmos, ear and nose anomalies, cutaneous syndactyly, genital malformations, laryngeal stenosis, and renal anomaly. ${ }^{2-4}$ Because 
cryptophthalmos appears not to be an essential component of the syndrome, the designation Fraser syndrome is preferable and has been previously advocated. ${ }^{2} 56$

Concordant monozygotic twins with bilateral renal agenesis have been described only once. ${ }^{7}$ This report provides a description of monozygotic twins concordant for bilateral renal agenesis with additional malformations suggestive of Fraser syndrome, so that this very unusual association is readily explained by an autosomal recessive mode of inheritance.

\section{Case report}

The mother was a 30 year old gravida 3 , para $2+0$. Five years earlier she had had a normal female infant at term weighing $3.46 \mathrm{~kg}$, and three years previously she had had a normal male infant at 39 weeks' gestation weighing $3.75 \mathrm{~kg}$. She had a seronegative polyarthropathy but was on no medical treatment other than folic acid and iron supplementation. Insulin dependent diabetes mellitus affected her maternal grandmother and aunt. Her husband was 36 years of age and in good health. They were not related. Three of their parents came from the west coast of Ireland. There was no family history of renal abnormalities.

In this pregnancy she presented at 11 weeks' gestation. Ultrasound examination showed the presence of twin pregnancy compatible with her dates. A second ultrasound at 27 weeks' gestation revealed only one fetal heart and a diagnosis of missed abortion of the crumpled co-twin was made. Repeat ultrasound at 32 to 37 weeks suggested increasing growth retardation of the surviving twin. Just before 38 weeks' gestation elective Caesarian section was performed for severe oligohydramnios and abnormal cardiotocograph tracing. At Caesarian section a severely abnormal looking female infant was delivered, weighing $2 \cdot 15 \mathrm{~kg}$. A fetus papyraceous was also present. The liveborn infant had typical Potter's facies with compressed ears, small nose and chin, a characteristic epicanthic fold, an aged appearance, and large spade-shaped hands with partial syndactyly of the third and fourth fingers. There was no evidence of cryptophthalmos. The external genitalia were female and there was marked hypertrophy of the clitoris with partial fusion of the labia majora anterior to the vaginal opening. This twin survived for 32 minutes.

The placenta was a single disc with a monochorionic diamniotic septum. The portion of the placenta corresponding to the liveborn infant showed cord oedema and prominent amnion nodosum. The other side of the placenta contained a fetus papyraceus with bilateral renal agenesis. The fetus papyraceus had a foot length of $2.4 \mathrm{~cm}$ suggesting that it survived until approximately 16 weeks' gestation. Necropsy findings of the liveborn infant revealed bilateral renal agenesis with absence of ureters and bladder. The uterus was hypoplastic. Additional abnormalities included laryngeal stenosis, abnormally short small intestine, wide fontanelles with polymicrogyria, single left palmar crease, and partial syndactyly of the third and fourth fingers bilaterally. Ocular histopathology was normal. The cause of death was postpartum asphyxia due to pulmonary hypoplasia, and this was manifested by epicardial and subpleural petechial haemorrhages. Cytomegaly was present in the fetal adrenal cortex bilaterally. Chromosome analysis revealed a normal female karyotype.

\section{Discussion}

This is the second recorded case of monozygotic twins concordant for bilateral renal agenesis and an interesting sequel to the earlier report from this unit. ${ }^{7}$ These and other reports of sibships in which more than one subject has been affected ${ }^{8}$ provide evidence for a genetic component in the aetiology of bilateral renal agenesis, but in this case the presence of associated malformations suggests that the renal agenesis was part of an inherited syndrome.

A large family study of renal agenesis by Carter $e t$ $a l^{8}$ included a male index case with bilateral renal agenesis and unilateral cryptophthalmos whose sister also had bilateral renal agenesis with syndactyly and laryngeal atresia. Cryptophthalmos syndrome was put forward as a possible diagnosis and further support for this suggestion came later with the birth of another child with bilateral renal agenesis, laryngeal obstruction, and deficiency of the medial third of one upper eyelid. ${ }^{5}$ This demonstrated that cryptophthalmos is not an invariable component of the cryptophthalmos syndrome and prompted the authors to suggest that Fraser syndrome would be a more appropriate name.

In our family the liveborn twin had syndactyly and laryngeal stenosis so that Fraser syndrome is again a likely diagnosis. This condition is inherited as an autosomal recessive trait which would readily explain the rare association of bilateral renal agenesis in monozygotic twins.

This report provides further evidence that cryptophthalmos is not an essential component of the cryptophthalmos syndrome and we would support the view that Fraser syndrome is a better name for this condition. In cases of bilateral renal agenesis this is an important diagnosis to consider because of the much increased recurrence risk, and the features 
of this syndrome should be excluded by careful necropsy examination. It has been pointed out that the recurrence rate in bilateral renal agenesis is too high to be explained on the basis of multifactorial inheritance unless estimates of the birth frequency are much too low. ${ }^{8}$ Single gene defects could account for some of this excess and Fraser syndrome is one likely candidate.

We are grateful to the late Professor C O Carter for his helpful comments on this case. We would also like to thank Mrs C McIntyre who typed the manuscript.

\section{References}

1 Azevedo ES, Biondi J, Ramalho LM. Cryptophthalmos in two families from Bahia, Brazil. J Med Genet 1973;10:389-92.
2 Smith DW. Recognizable patterns of human malformation. 3rd ed. Philadelphia: Saunders, 1982:179.

${ }^{3}$ François J. Syndrome malformatif avec cryptophthalmie. Acta Genet Med Gemellol (Roma) 1969;18:18-50.

${ }^{4}$ Fraser CR. Our genetic 'load'. A review of some aspects of genetic variation. Ann Hum Genet 1962;25:387-415.

5 Burn J, Marwood RP. Fraser syndrome presenting as bilateral renal agenesis in three sibs. $J$ Med Genet 1982;19:360-1.

${ }^{6}$ McKusick VA. Mendelian inheritance in man. 6th ed. Baltimore, London: Johns Hopkins University Press, 1983.

7 Yates JRW, Mortimer G, Connor JM, Duke JE. Concordant monozygotic twins with bilateral renal agenesis. $J$ Med Genet 1984;21:66-7.

${ }^{8}$ Carter CO, Evans K, Pescia G. A family study of renal agenesis. J Med Genet 1979;16:176-88.

Correspondence and requests for reprints to $\mathrm{Dr} G$ Mortimer, Department of Pathology, Royal Maternity Hospital, Glasgow G4 0NA.

\title{
Familial opposable triphalangeal thumbs associated with duplication of the big toes
}

\author{
PAUL MERLOB, MICHAEL GRUNEBAUM, AND SALOMON H REISNER
}

Departments of Neonatology and Pediatric Radiology, Beilinson Medical Center, Petah Tiqva, and the Sackler School of Medicine, Tel Aviv University, Tel Aviv, Israel.

SUMMARY A rare association of triphalangeal thumbs and duplication of the big toes is described. The family pedigree confirms autosomal dominant inheritance with marked penetrance. A systematic approach to the diagnosis of this anomaly is presented. The distinction between the two types of triphalangeal thumb, true (opposable) and fingerlike (non-opposable), is emphasised.

A triphalangeal thumb is defined as a thumb with three phalanges in a row. This is a very rare congenital malformation. Wood ${ }^{1}$ reviewed published reports and found 362 patients with 630 triphalangeal thumbs. About two-thirds of these cases had a family history.' However, the familial occurrence of opposable triphalangeal thumbs with duplication of the big toes has rarely been reported. ${ }^{2-5}$ We wish to report a family with this anomaly and to suggest a systematic approach to the infant with triphalangeal thumbs.

\section{Case report}

The family pedigree is shown in fig 1 . The first child

Received for publication 27 January 1984. Accepted for publication 1 June 1984
(V.1) was born in 1981 after a normal pregnancy and delivery to a 30 year old, G2, P1, A1 healthy mother. The parents were unrelated. The pregnancy was normal. There was no history of any medication, alcohol intake, or smoking during pregnancy.

Physical examination revealed a healthy female infant with malformations of both thumbs and big toes. Both thumbs were affected symmetrically. They appeared long with an additional interphalangeal joint and an extra set of skin creases. The thenar region, the first web space, and the nail were

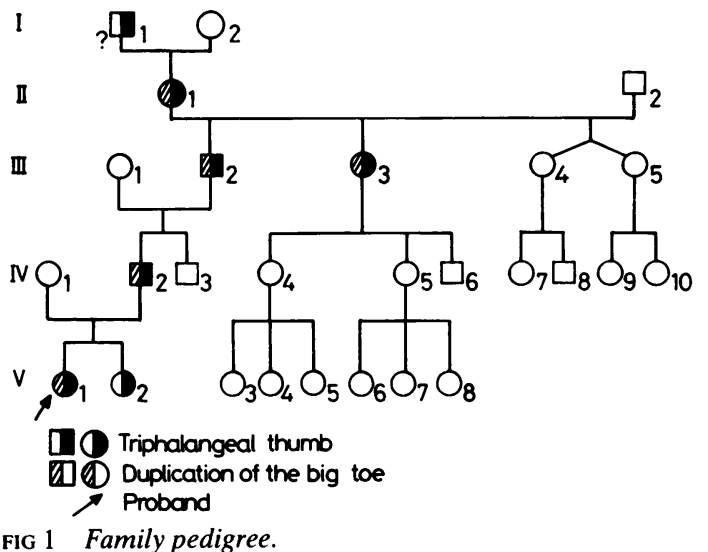

